\title{
Investigation of the ZNF804A gene polymorphism with genetic risk for bipolar disorder in attention deficit hyperactivity disorder
}

Xiaohui Xu ${ }^{1 *}$, Gerome Breen', Lucy Luo ${ }^{2}$, Bo Sun², Chih-Ken Chen ${ }^{3,4,5}$, Ursula M Paredes' ${ }^{1}$ Yu-Shu Huang ${ }^{4,5}$, Yu-Yu Wu $\mathrm{Wu}^{4,5}$ and Philip Asherson ${ }^{1}$

\begin{abstract}
Background: Genome-wide association studies (GWAS) have been conducted on many psychiatric disorders. Evidence from large GWAS indicates that the single nucleotide polymorphism (SNP) rs1344706 in the zinc-finger protein 804A gene (ZNF804A) is associated with psychotic disorders including bipolar disorder and schizophrenia. One study also found significant association between rs1344706 and the executive control network of attention. In this study we examine the role of the rs 1344706 polymorphism that previously showed association with BD and is known to alter expression of the gene in two clinical family-based ADHD samples from the UK and Taiwan.

Findings: To investigate the association between rs1344706 and ADHD, two family samples of ADHD probands from the United Kingdom $(n=180)$ and Taiwan $(n=212)$ were genotyped using TaqMan SNP genotyping assays and analysed using within-family transmission disequilibrium test. No significant associations were found between rs1344706 polymorphism and ADHD in either of the samples from Taiwan $(P=0.91)$ and UK $(P=0.41)$. Even combining the two datasets together the A allele of rs1344706 SNP was still not significantly over-transmitted to affected probands $(P=0.50)$. Furthermore, there was no evidence of association with the specific symptoms subgroups of inattention or hyperactivity-impulsivity.

Conclusions: In this study we used family-based ADHD data in the UK and Taiwanese population to test for an association between rs1344706 SNP in the ZNF804A gene and ADHD. Results showed no significant association of rs1344706 with ADHD in UK and Taiwanese samples.
\end{abstract}

Keywords: Attention deficit hyperactivity disorder, ZNF804A, Single nucleotide polymorphism, Association study, Bipolar disorder

\section{Findings}

\section{Background}

Attention deficit hyperactivity disorder (ADHD) is one of the most frequent and heritable neurodevelopmental disorders of childhood characterised by developmentally inappropriate and impairing levels of inattention, hyperactivity and impulsivity. Current estimates show that $3 \%-5 \%$ of school age children have a diagnosis of ADHD [1]. The disorder persists into adulthood in around twothirds of cases [2]. ADHD has been associated with a

\footnotetext{
* Correspondence: xiaohui.xu@kcl.ac.uk

${ }^{1}$ MRC Social, Genetic and Developmental Psychiatry Centre, Institute of Psychiatry, King's College London, London, UK

Full list of author information is available at the end of the article
}

number of psychiatric comorbidities, including major depressive disorder (MDD), bipolar disorder (BD) and anxiety disorder [3-5]. In particular ADHD and BD present with some overlapping clinical characteristics and diagnostic criteria. Several studies have reported the occurrence of high rates of emotional lability and increased rates of depression in both child and adults patients with ADHD [6-10]. The evidence relating to $\mathrm{BD}$ and its potential link with ADHD has been reviewed extensively $[5,6]$ and points to a significant link with evidence from clinical, epidemiological, family and neuroimaging studies. Review of clinical and epidemiological studies found that the increased rate of comorbidity between ADHD and bipolar disorder may be greater

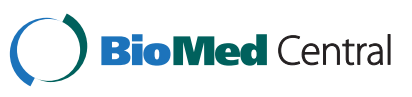

(c) 2013 Xu et al.; licensee BioMed Central Ltd. This is an Open Access article distributed under the terms of the Creative Commons Attribution License (http://creativecommons.org/licenses/by/2.0), which permits unrestricted use, distribution, and reproduction in any medium, provided the original work is properly cited. 
than that seen with other psychiatric comorbidities of ADHD [6]. Findings from studies of children with ADHD suggested that combined subtype of ADHD may be at particularly higher risk of developing $\mathrm{BD}[6,11]$.

A wide variety of candidate genes have been investigated in ADHD and other psychiatric disorders including $\mathrm{BD}$, with some genes reported to be associated with both ADHD and BD [12-16]. For example, a recent findings support the hypothesis that variation within circadian clock genes contribute to $\mathrm{BD}$ and related illnesses like ADHD, MDD and schizophrenia [17]. With regard to ADHD and schizophrenia, there are now several papers showing that rare copy number variants affecting some genes are associated with both ADHD and schizophrenia (SZ) [18-20]. The biological mechanisms that underlie these shared genetic influences remain uncertain, but could be related to common neurodevelopmental processes, or aberrations of neurotransmitter systems such as dopamine.

GWAS studies on ADHD have yet to identify SNPs associations with genome-wide significance [21]. However, promising findings from GWAS have emerged for other psychiatric disorders, particularly SZ and BD. GWAS identified strong evidence for association of the zinc finger protein 804A (ZNF804A) gene (located on the long arm of chromosome 2 at the $2 \mathrm{q} 32.1$ ) with psychiatric disorders including both BD and SZ $[22,23]$. One recent GWAS reported association between rs1344706 in $Z N F 804 A$ and schizophrenia $(P=1.61 \times$ $10^{-7}$ ), and found strong evidence when the affected phenotype included patients with bipolar disorder $\left(P=9.96 \times 10^{-9}\right)$ [22]. Several replication studies confirmed the association [24-27]. Meta-analysis of a larger dataset found very strong evidence for association between rs1344706 and schizophrenia $\left(P=2.54 \times 10^{-11}\right)$ and a combined schizophrenia/bipolar phenotype $\left(P=4.1 \times 10^{-13}\right)$ [23]. Balog et al., [28] investigated the relationship between rs1344706 in ZNF804A and attention in 200 healthy volunteers and found a significant association with a measure of the executive control attention network. One recent study examined six SNPs in five genes in adult ADHD, and concluded that the six SNPs including rs1344706 in ZNF804A, which showed strong evidence of association with bipolar disorder, did not appear to be associated with ADHD [29].

As ADHD and BD are both highly heritable, show comorbidity with each other and an increased crossdisorder familial risk [30,31], the aim of the present study was to provide further investigation of genetic evidence linking ADHD and bipolar disorder. We examine the role of the rs1344706 polymorphism in ZNF804A in two clinical ADHD samples from the UK and Taiwan.

\section{Materials and methods Subjects The UK ADHD sample}

DNA was collected from 180 ADHD combined subtype probands. Both parents were available for 116 families, and only the mother was available for 64 families. Ninety-six percent of the sample was male. Cases were recruited from child behaviour clinics and referred for assessment if they were thought by experienced clinicians to have a diagnosis of combined subtype ADHD under DSM-IV criteria, with no significant Axis I comorbidity apart from oppositional defiant disorder (ODD, 5.5\% of sample) and conduct disorder (CD, 15.5\% of sample). Intelligence quotient (IQ) was assessed using the Wechsler Intelligence Scale for Children-Third Edition (WISC-III). Exclusion criteria included IQ less than 70, neurological disorders, brain damage or autism. Only those individuals fulfilling the recruitment criteria after completion of research assessments were included in the study. All probands were of European-Caucasian origin. The age range was 5-15 years at the time of assessment (mean 10.41, SD 2.34). Parents were interviewed with a modified version of the Child and Adolescent Psychiatric Assessment (CAPA) [32]. Information on ADHD symptoms at school was obtained using the teacher Conner's revised questionnaire [33]. The subjects gave their written informed consent and were approved by the ethical committee of King's College London (Reference number: G9814668).

\section{Taiwanese ADHD sample}

Samples were collected from 212 children with ADHD diagnosed between the ages of 5-15 years (mean 8.96, SD 2.60), from both parents for 114 families of the ADHD probands and from only the mother for 59 families or only the father for 39 families. ADHD cases were ascertained from Child Psychiatric Clinics in the Chang Gung Memorial Hospital in Taipei area, Taiwan. The diagnosis of ADHD was made under DSM-IV criteria following completion of a standard maternal interview [34] and completion of Conners' parent and teacher revised rating scales [33]. Seventy-eight percent of the sample had combined subtype ADHD and $22 \%$ had inattentive subtype ADHD, with no co-morbid disorders apart from ODD (5.2\%), CD (9.4\%) and Tourettes syndrome $(1.8 \%)$. Cases with autism were excluded from the study. Eighty-nine percent of the sample was male, $87 \%$ had IQ greater than 69 and 13\% had IQ between 50-69. All subjects gave their written informed consent, and were approved by the Institutional Review Board, Chang Gung Memorial Hospital, Taiwan (Reference number: 96-0058B). 


\section{Genotyping}

The rs1344706 polymorphism was genotyped using a TaqMan ${ }^{\circledR}$ SNP genotyping assay (Assay ID: C_2834835_10) on a $7900 \mathrm{HT}$ sequence detection system (Applied Biosystems). The distribution of the genotypes did not deviate from Hardy-Weinberg equilibrium $(P>0.05)$.

\section{Statistics}

Genotype data from probands and parents were analysed using the transmission disequilibrium test (TDT) implemented in the UNPHASED program (TDTPHASE) [35]. http://www.mrc-bsu.cam.ac.uk/personal/frank/software/ unphased/.

\section{Results}

Population frequencies for SNP rs1344706 (an A/C polymorphism) were estimated from parental genotypes. For the UK and the Taiwanese sample the A-allele frequency was $61 \%$ and $55 \%$, respectively. There was no significant difference in allele frequencies between the two populations $\left(\chi^{2}=0.390, \mathrm{df}=1, \quad P=0.474\right) ;$ and genotype frequencies did not deviate from Hardy-Weinberg equilibrium in either population.

TDT analysis (Table 1) showed no evidence of increased transmission of the A allele in either of the samples (Taiwan: $X^{2}=0.012, P=0.91$; UK: $X^{2}=0.667$, $P=0.41)$. When the two datasets were combined, the A allele was still not significantly over-transmitted to affected probands $\left(\chi^{2}=0.458, P=0.50\right)$.

We further explored the subtypes of ADHD. We found that there was no association between rs1344706 and ADHD in the subgroup of the Taiwanese sample with the inattentive subtype $\left(\chi^{2}=0.604, P=0.437\right)$. We were not able to investigate the hyperactive-impulsive subtype separately because neither samples included any such cases. To investigate whether there were any associations with the specific symptom domains of ADHD, we therefore completed an additional analysis using quantitative ratings of parent rated inattentive and hyperactive-impulsive symptoms using quantitative pedigree disequilibrium test (QPDT) from the UNPHASED program. The results from QPDT analysis showed that the A allele of rs1344706 was not associated with either symptom domain in samples from UK ( $Z$-score $=-0.214 ; P=0.830$ for inattentive symptoms;
$Z$-score $=0.416 ; \quad P=0.677$ for hyperactive-impulsive symptoms) or Taiwan ( $Z$-score $=0.253 ; P=0.801$ for inattentive symptoms; $Z$-score $=0.220 ; \quad P=0.826$ for hyperactive-impulsive symptoms). When the two datasets were combined, the A allele was still not significantly associated with either symptom domain ( $Z$-score $=$ -0.293; $P=0.769$ for inattentive symptoms; $Z$-score $=$ $0.049 ; P=0.961$ for hyperactive-impulsive symptoms).

\section{Discussion}

In this study we set out to investigate association between SNP rs1344706 in the ZNF804A gene, which was previously found to be associated with $\mathrm{BD}$, and ADHD in two independent ADHD samples from the UK and Taiwan. No association was observed between this polymorphism and ADHD in either sample or when the two samples were pooled together. We further investigated the association on specific symptom subgroups of ADHD. We found no association with the subgroup of the Taiwanese samples with DSM-IV inattentive subtype. Furthermore, using a quantitative trait approach there was no evidence of association with quantitative ratings of either inattentive or hyperactive-impulsive symptoms in either sample.

The human $Z N F 804 A$ gene is located on the long arm of chromosome 2 at the $2 \mathrm{q} 32.1$ and ZNF804A encodes the transcription factor zinc-finger protein 804A. SNP rs1344706 lies in intron 2 of ZNF804A and the A allele is predicted to enhance the maintenance of binding sites for brain-expressed transcription factors [24]. ZNF804A gene shows strong evidence of association with both $\mathrm{BD}$ and SZ from GWAS [22,23]. The association between SNPs in the Zinc finger gene and ADHD has been suggested before, but a study investigating the relationship between six SNPs reported to be associated with BD, including SNP rs1344706, were not associated in a samples of adults with ADHD. However, a weak association was however observed in the study between rs1344706 and a positive MDQ score, suggesting a possible association with risk for the development of mood symptoms in adult patients with ADHD [29]. Data from another study suggest that rs1344706 is associated with increased response latency on a task assessing the executive control network of attention in healthy adult volunteers [28].

Table 1 Results of TDT analysis for rs1344706 polymorphism

\begin{tabular}{|c|c|c|c|c|c|c|}
\hline & \multicolumn{2}{|c|}{ UK samples } & \multicolumn{2}{|c|}{ Taiwanese samples } & \multicolumn{2}{|c|}{ Combined samples } \\
\hline & \multicolumn{2}{|c|}{ Allele } & \multicolumn{2}{|c|}{ Allele } & \multicolumn{2}{|c|}{ Allele } \\
\hline & A & C & A & $\mathrm{C}$ & A & C \\
\hline Transmitted & 44 & 52 & 40 & 41 & 84 & 93 \\
\hline Non-transmitted & 52 & 44 & 41 & 40 & 93 & 84 \\
\hline$X^{2}, \mathrm{df}$ (P-value) & \multicolumn{2}{|c|}{$0.667,1 \mathrm{df}(0.41)$} & \multicolumn{2}{|c|}{$0.012,1 \mathrm{df}(0.91)$} & \multicolumn{2}{|c|}{$0.458,1 \mathrm{df}(0.50)$} \\
\hline
\end{tabular}


In our study we used family-based ADHD data from the UK and Taiwan to investigate the role between rs1344706 and ADHD. The study presents several limitations that need to be considered. The sample was relatively small and might therefore be underpowered to exclude very small genetic effects. Furthermore, the subgroup with inattentive subtype ADHD was only $22 \%$ of the Taiwanese sample and none of the UK sample. Only one polymorphism was genotyped in this gene, therefore we cannot exclude the possibility of association between multiple SNP haplotypes and ADHD.

\section{Conclusion}

This study found no evidence of an association between SNP rs1344706 in ZNF804A and ADHD in UK and Taiwanese samples. Due to the limitation of sample size in our study and the fact that, to our knowledge, there is only one published study examining association between rs1344706 and ADHD in adult samples, further association studies are required to investigate the role of the high-risk ZNF804A SNPs in ADHD. ZNF804A is a protein currently of unknown function. However, the risk allele of rs1344706 associated with other major mental illnesses has been shown to be associated with higher ZNF804A expression [24]. Further work should focus on identifying any additional functional polymorphisms of this gene for investigation in further samples of clinical disorders that share genetic risks with either bipolar disorder or schizophrenia.

\section{Competing interests}

The authors declare that they have no competing interests.

\section{Authors' contributions}

XX selected the SNP, performed genotyping and drafted the manuscript. GB supervised the study and revised the manuscript. $L L$ and BS analysed genetic data. UMP helped to do genotyping. CKC, YSH and YYW provided the Taiwanese DNA samples and clinical data. CKC also revised the manuscript. PA supervised the study and revised the paper. All authors contributed to the final critical revision of the manuscript.

\section{Acknowledgements}

This research was funded by The Wellcome Trust (No.079314/4/2/06/2). The study was also supported by the Department of Psychiatry of Chang Gung Memorial Hospital in Taiwan. We thank Dr Karim Malki who helped revise the manuscript and anonymous reviewers for their helpful suggestions. We also thank the families who took part in this research and Dr Keeley Brookes who helped prepare the UK samples.

\section{Author details \\ ${ }^{1}$ MRC Social, Genetic and Developmental Psychiatry Centre, Institute of Psychiatry, King's College London, London, UK. ${ }^{2}$ School of Medicine, King's College London, London, UK. ²Department of Psychiatry, Chang Gung Memorial Hospital, Taoyuan, Taiwan. ${ }^{4}$ Chang Gung University School of Medicine, Taoyuan, Taiwan. ${ }^{5}$ Division of Mental Health \& Drug Abuse Research, National Health Research Institutes, Taoyuan, Taiwan.}

Received: 10 July 2012 Accepted: 23 January 2013

Published: 26 January 2013

\section{References}

1. Polanczyk G, de Lima MS, Horta BL, Biederman J, Rohde LA: The worldwide prevalence of ADHD: a systematic review and metaregression analysis. Am J Psychiatry 2007, 164:942-948.

2. Biederman J, Faraone SV, Keenan K, Knee D, Tsuang MT: Family-genetic and psychosocial risk factors in DSM-III attention deficit disorder. J Am Acad Child Adolesc Psychiatry 1990, 29:526-533.

3. McGough JJ, Smalley SL, McCracken JT, Yang M, Del'Homme M, Lynn DE, Loo S: Psychiatric comorbidity in adult attention deficit hyperactivity disorder: findings from multiplex families. Am J Psychiatry 2005, 162:1621-1627.

4. Fischer $A G$, Bau CH, Grevet EH, Salgado CA, Victor MM, Kalil KL, Sousa NO, Garcia CR, Belmonte-de-Abreu P: The role of comorbid major depressive disorder in the clinical presentation of adult ADHD. J Psychiatr Res 2007, 41:991-996.

5. Klassen LJ, Katzman MA, Chokka P: Adult ADHD and its comorbidities, with a focus on bipolar disorder. J Affect Disord 2010, 124:1-8.

6. Skirrow C, Hosang GM, Farmer AE, Asherson P: An update on the debated association between ADHD and bipolar disorder across the lifespan. $J$ Affect Disord 2012, 141:143-159.

7. Wilens TE, Biederman J, Wozniak J, Gunawardene S, Wong J, Monuteaux M: Can adults with attention-deficit/hyperactivity disorder be distinguished from those with comorbid bipolar disorder? Findings from a sample of clinically referred adults. Biol Psychiatry 2003, 54:1-8.

8. Nierenberg AA, Miyahara S, Spencer T, Wisniewski SR, Otto MW, Simon N, Pollack MH, Ostacher MJ, Yan L, Siegel R, Sachs GS: TEP-BD Investigators: Clinical and diagnostic implications of lifetime attention-deficit/ hyperactivity disorder comorbidity in adults with bipolar disorder: data from the first 1000 STEP-BD participants. Biol Psychiatry 2005, 57:1467-1473

9. Tamam L, Tuğlu C, Karatas G, Ozcan S: Adult attention-deficit hyperactivity disorder in patients with bipolar I disorder in remission: preliminary study. Psychiatry Clin Neurosci 2006, 60:480-485.

10. Tamam L, Karakus G, Ozpoyraz N: Comorbidity of adult attention-deficit hyperactivity disorder and bipolar disorder: prevalence and clinical correlates. Eur Arch Psychiatry Clin Neurosci 2008, 258:385-393.

11. Donfrancesco R, Miano S, Martines F, Ferrante L, Melegari MG, Masi G: Bipolar disorder co-morbidity in children with attention deficit hyperactivity disorder. Psychiatry Res 2011, 186:333-337.

12. $X u X$, Brookes $K$, Chen CK, Huang YS, Wu YY, Asherson P: Association study between the monoamine oxidase $A$ gene and attention deficit hyperactivity disorder in Taiwanese samples. BMC Psychiatry 2007, 7:10

13. Li J, Wang Y, Zhou R, Zhang H, Yang L, Wang B, Faraone SV: Association between polymorphisms in serotonin transporter gene and attention deficit hyperactivity disorder in Chinese Han subjects. Am J Med Genet B Neuropsychiatr Genet 2007, 144B:14-19.

14. Matthews N, Vance A, Cummins TD, Wagner J, Connolly A, Yamada J, Lockhart PJ, Panwar A, Wallace RH, Bellgrove MA: The COMT Val158 allele is associated with impaired delayed-match-to-sample performance in ADHD. Behav Brain Funct 2012, 8:25.

15. Jones I, Craddock N: Candidate gene studies of bipolar disorder. Ann Med 2001, 33:248-256.

16. Craddock N, Davé S, Greening J: Association studies of bipolar disorder. Bipolar Disord 2001, 3:284-298.

17. McCarthy MJ, Nievergelt CM, Kelsoe JR, Welsh DK: A survey of genomic studies supports association of circadian clock genes with bipolar disorder spectrum illnesses and lithium response. PLoS One 2012, 7:e32091.

18. Elia J, Gai X, Xie HM, Perin JC, Geiger E, Glessner JT, D'Arcy M, DeBerardinis R, Frackelton E, Kim C, Lantieri F, Muganga BM, Wang L, Takeda T, Rappaport EF, Grant SF, Berrettini W, Devoto M, Shaikh TH, Hakonarson H, White PS: Rare structural variants found in attention-deficit hyperactivity disorder are preferentially associated with neurodevelopmental genes. Mol Psychiatry 2010, 15:637-646.

19. Williams NM, Zaharieva I, Martin A, Langley K, Mantripragada K, Fossdal R, Stefansson H, Stefansson K, Magnusson P, Gudmundsson OO, Gustafsson O, Holmans P, Owen MJ, O'Donovan M, Thapar A: Rare chromosomal deletions and duplications in attention-deficit hyperactivity disorder: a genome-wide analysis. Lancet 2010, 376:1401-1408.

20. Williams NM, Franke B, Mick E, Anney RJ, Freitag CM, Gill M, Thapar A, O'Donovan MC, Owen MJ, Holmans P, Kent L, Middleton F, Zhang-James Y, 
Liu L, Meyer J, Nguyen TT, Romanos J, Romanos M, Seitz C, Renner TJ, Walitza S, Warnke A, Palmason H, Buitelaar J, Rommelse N, Vasquez AA, Hawi Z, Langley K, Sergeant J, Steinhausen HC, et al: Genome-wide analysis of copy number variants in attention deficit hyperactivity disorder: the role of rare variants and duplications at 15q13.3. Am J Psychiatry 2012, 169:195-204.

21. Franke B, Neale BM, Faraone SV: Genome-wide association studies in ADHD. Hum Genet 2009, 126:13-50.

22. O'Donovan MC, Craddock N, Norton N, Williams H, Peirce T, Moskvina V, Nikolov I, Hamshere M, Carroll L, Georgieva L, Dwyer S, Holmans P, Marchini JL, Spencer CC, Howie B, Leung HT, Hartmann AM, Möller HJ, Morris DW, Shi Y, Feng G, Hoffmann P, Propping P, Vasilescu C, Maier W, Rietschel M, Zammit S, Schumacher J, Quinn EM, Schulze TG, et al: Identification of loci associated with schizophrenia by genome-wide association and followup. Nat Genet 2008, 40:1053-1055.

23. Williams HJ, Norton N, Dwyer S, Moskvina V, Nikolov I, Carroll L, Georgieva L, Williams NM, Morris DW, Quinn EM, et al: Fine mapping of ZNF804A and genome-wide significant evidence for its involvement in schizophrenia and bipolar disorder. Mol Psychiatry 2011, 6:429-441.

24. Riley B, Thiselton D, Maher BS, Bigdeli T, Wormley B, McMichael GO, Fanous AH, Vladimirov V, O'Neill FA, Walsh D, Kendler KS: Replication of association between schizophrenia and ZNF804A in the Irish Case-control Study of Schizophrenia sample. Mol Psychiatry 2010, 15:29-37.

25. Hashimoto R, Ohi K, Yasuda Y, Fukumoto M, Iwase M, like N, Azechi M, Ikezawa K, Takaya M, Takahashi H, Yamamori H, Okochi T, Tanimukai H, Tagami S, Morihara T, Okochi M, Tanaka T, Kudo T, Kazui H, Iwata N, Takeda $M$ : The impact of a genome-wide supported psychosis variant in the ZNF804A gene on memory function in schizophrenia. Am J Med Genet B Neuropsychiatr Genet 2010, 153B:1459-1464.

26. Steinberg S, Mors O, Børglum AD, Gustafsson O, Werge T, Mortensen PB, Andreassen OA, Sigurdsson E, Thorgeirsson TE, Böttcher Y, Olason P, Ophoff RA, Cichon S, Gudjonsdottir IH, Pietiläinen OP, Nyegaard M, TuulioHenriksson A, Ingason A, Hansen T, Athanasiu L, Suvisaari J, Lonnqvist J, Paunio T, Hartmann A, Jürgens G, Nordentoft M, Hougaard D, NorgaardPedersen B, Breuer R, Möller HJ, et al: Expanding the range of ZNF804A variants conferring risk of psychosis. Mol Psychiatry 2011, 16:59-66.

27. Zhang R, Lu SM, Qiu C, Liu XG, Gao CG, Guo TW, Valenzuela RK, Deng HW, Ma J: Population-based and family-based association studies of ZNF804A locus and schizophrenia. Mol Psychiatry 2011, 16:360-361.

28. Balog Z, Kiss I, Kéri S: ZNF804A may be associated with executive control of attention. Genes Brain Behav 2011, 10:223-227.

29. Landaas ET, Johansson S, Halmøy A, Oedegaard KJ, Fasmer OB, Haavik J: Bipolar disorder risk alleles in adult ADHD patients. Genes Brain Behav 2011, 10:418-423.

30. Faraone SV, Biederman J, Mennin D, Wozniak J, Spencer T: Attention-deficit hyperactivity disorder with bipolar disorder: a familial subtype? J Am Acad Child Adolesc Psychiatry 1997, 36:1378-1390.

31. Birmaher B, Axelson D, Goldstein B, Monk K, Kalas C, Obreja M, Hickey MB, lyengar S, Brent D, Shamseddeen W, Diler R, Kupfer D: Psychiatric disorders in preschool offspring of parents with bipolar disorder: the Pittsburgh Bipolar Offspring Study (BIOS). Am J Psychiatry 2010, 167:321-330.

32. Angold A, Prendergast M, Cox A, Harrington R, Simonoff E, Rutter M: The Child and Adolescent Psychiatric Assessment (CAPA). Psychol Med 1995, 25:739-753.

33. Conners CK: The Conners Rating Scales: Instruments for Assessments of Childhood Psychopathology. Durham, USA: Duke University; 1995.

34. Kaufman J, Birmaher B, Brent D, Rao U, Flynn C, Moneci P, Williamson D, Ryan N: Schedule for affective disorders and schizophrenia for schoolage children-present and lifetime version (K-SADS-PL): initial reliability and validity data. J Am Acad Child Adolesc Psychiatry 1997, 36:980-988.

35. Dudbridge F: Pedigree disequilibrium tests for multilocus haplotypes. Genet Epidemiol 2003, 25:115-121.

doi:10.1186/1756-0500-6-29

Cite this article as: Xu et al:: Investigation of the ZNF804A gene polymorphism with genetic risk for bipolar disorder in attention deficit hyperactivity disorder. BMC Research Notes 2013 6:29.

\section{Submit your next manuscript to BioMed Central and take full advantage of:}

- Convenient online submission

- Thorough peer review

- No space constraints or color figure charges

- Immediate publication on acceptance

- Inclusion in PubMed, CAS, Scopus and Google Scholar

- Research which is freely available for redistribution 